\title{
Emulgel based topical delivery system for loratadine
}

\author{
Vijay Kumar $^{1}$, Sheefali Mahant ${ }^{2} \underline{\underline{ }}$, Rekha Rao $^{3}$, Sanju Nanda ${ }^{2}$ \\ ${ }^{1}$ MM College of Pharmacy, MM University, Mullana-Ambala, India- 133207 \\ ${ }^{2}$ Department of Pharmaceutical Sciences, Maharshi Dayanand University, Rohtak, India- 124001 \\ ${ }^{3}$ Department of Pharmaceutical Sciences, Guru Jambeshwar University of Science \& Technology, Hisar, India- 125001 \\ ${ }^{\square}$ Corresponding Author: Sheefali Mahant E-mail: sheefali.m@gmail.com; Tel.: +91-9416327336
}

Received: August 27, 2014; Revised: November 27, 2014; Published: January 09, 2015

\begin{abstract}
The present study was taken up with the objective of formulating emulgels to facilitate topical delivery of loratadine in the treatment of localized skin allergy. It was attempted to prepare the emulgels using three different types of surfactants, i.e. cationic, non-ionic and anionic. Further, the aim was to compare the formulations for their drug release and stability. Loratadine was incorporated into an o/w system, which was, subsequently, gellified using Carbopol 940. The resulting emulgels were subject to tests for physical characteristics. Thereafter, ex vivo drug release study, skin irritation test and in vivo test for anti-allergic activity were also carried out. A considerably higher drug release was recorded from the emulgel formulated with the cationic surfactant, cetrimide. Drug release kinetics was investigated by fitting the drug release data into various models. The drug release from all the formulations was found to follow zero-order kinetics. In addition, the prepared emulgels exhibited satisfactory physical characteristics and good stability. Besides being non-irritant to the skin, they were effective in alleviating symptoms of skin allergy.
\end{abstract}

\section{Keywords}

gellified emulsion; cetrimide; allergy; surfactant; carbopol; sodium lauryl sulphate; Tween; Span

\section{Introduction}

Allergy (hypersensitivity) may be defined as untoward immunological reaction to an environmental immunogen, called allergen. Allergy mainly results due to the release of inflammatory mediators such as histamine, leukotrienes, etc. from the mast cells. Skin allergy is characterized by symptoms such as rash, angioedema, inflammation, pain, irritation, pruritis, urticaria and wheals [1-3]. According to the American Academy of Allergy, Asthma and Immunology, there has been a continuous rise in the prevalence of allergy in industrialized nations for more than fifty years. Worldwide, urticaria is reported to have a lifetime prevalence of more than $20 \%$ [4]. In 2010, 9.4 million cases of skin allergy were reported in children in US $[5]$. 
The pharmacotherapy for skin allergy consists of administration of antihistamines, topical corticosteroids and systemic corticosteroids [6]. Antihistamines form the first-line treatment for skin allergy. Loratadine is a second generation $\mathrm{H}_{1}$-antihistaminic agent [7]. It is a BCS class II drug, having low molecular weight and high partition coefficient. It is typically administered by oral route [8]. Oral administration of the drug is associated with adverse effects like headache, nausea and fatigue. Moreover, the oral bioavailability of loratadine is poor [7]. In light of these facts, adopting the topical route for the delivery of loratadine would be useful in treating skin conditions characterized by localized allergic reaction.

Topical drug delivery can be defined as the application of a drug formulation to the skin to directly treat cutaneous disorders [9]. The topical agents use cutaneous delivery to specifically target the site of application. The sites of action for topical agents are the soft tissues and peripheral nerves underlying the site of application. In topical drug delivery systems, serum levels generally remain relatively low, as a result of which, the likelihood of systemic side effects or drug-drug interactions is abated. The vehicle in which the active ingredient(s) are delivered plays a significant role as it affects the depth of skin penetration and rate of absorption into the epidermis. Ideally, a topical agent should have a low molecular weight $\quad<500$ $\mathrm{Da}$ ) and possess both, hydrophobic as well as hydrophilic features, in order to traverse the stratum corneum and to penetrate the aqueous epidermis, respectively [10].

Emulgels or gellified emulsions are the topical formulations comprising of emulsion and gel, hence, possessing properties contributed by both. The oil phase, gelling agent and emulsifying agent constitute the major components of an emulgel system. Their concentrations significantly affect the rate and extent of drug release from the formulation [11].

Emulgels for dermatological use have several favorable properties such as being thixotropic, greaseless, easily spreadable, easily removable, emollient, non-staining, water soluble, more stable, bio-friendly, transparent and pleasant appearance. The advantages of emulgels include easy incorporation of hydrophobic drug into gel using oil-in-water emulsion system, increased stability, better loading capacity, and controlled release [11-14].Owing to the merits of emulgels over the conventional dermatological formulations, many drugs have been incorporated into them. Emulgels have been formulated for varied drug categories, such as non steroidal anti-inflammatory drugs, anti-fungal agents, anti-viral drugs, antibacterial drugs and local anaesthetics.

Topically, loratadine can be used in the therapy of disease or disorder characterized by hypersensititvity, such as urticaria, allergy based dermatoses (allergic skin reactions), atopical eczema, itching, redness, sunburn and insect bites [15].

The present study was taken up with the view to develop emulgels for dermal delivery of loratadine. Further, the aim was to formulate loratadine emulgels using three different types of emulsifying agents (cationic, anionic and non-ionic surfactants) and compare them for their drug release and stability. The formulation objectives were accomplished in two steps: the preliminary studies directed towards the formulation of stable emulsion systems and, the subsequent gellification stage, whereby stable emulsions were converted to emulgels. The emulgels so developed were subject to physicochemical characterization, ex vivo and in vivo evaluation and, investigation of drug release kinetics.

A study of the literature revealed that an emulgel formulation of loratadine has not been developed so far. Although, loratadine gel formulations have been developed [15], an emulgel has its own unique advantages. Loratadine, being a highly lipophilic drug, is an appropriate candidate to be incorporated in an 
oil-in-water emulgel. From the therapeutic standpoint, an emulgel would be more suitable for the treatment of skin allergies because of its emollient properties, attributed to the presence of an oily phase in the formulation. The emollience imparted by the oily phase would soothe the irritated skin. Additionally, the gel phase present in the formulation would allow prolonged release of the drug, apart from rendering elegance to the product.

\section{Experimental}

The materials used in the course of the present study are enlisted as follows: Loratadine, Carbopol 940 (Qualikem Fine Chem Ltd., Vadodara), sodium lauryl sulfate (Qualikem Fine Chem Ltd., Vadodara), cetrimide (Nice Chem Pvt. Ltd., Kochi), propylene glycol (Qualikem Fine Chem Ltd., Vadodara), light liquid paraffin (Qualikem Fine Chem Ltd., Vadodara), Tween 20 (Qualikem Fine Chem Ltd., New Delhi), methyl paraben (Qualikem Fine Chem Ltd. New Delhi), Span 20 (SDFCL, Mumbai), Cetyl alcohol (SDFCL, Mumbai), triethanolamine (Nice Chem Pvt. Ltd, Kochi), dichloromethane (Nice Chem Pvt. Ltd, Kochi), glyceryl monostearate (Loba Chemicals Pvt. Ltd, Mumbai), methanol (RFCL Ltd, New Delhi), ethanol (Changshu Yangyuan Chemicals, China).

To achieve the goal of the present study, different emulsifying agents were employed, based upon their ionic nature. Cetylpyridinium bromide (cetrimide) was taken as cationic surfactant, sodium lauryl sulfate as the anionic surfactant and, Span 20 and Tween 20 were used in the non-ionic category. In order to enhance product stability, glyceryl monostearate, cetyl alcohol and cetostearyl alcohol were incorporated as auxiliary emulsifying agents, in varying proportions. Carbopol 940, which is a hydrophilic polyacrylate polymer, was employed as the gelling agent. Light liquid paraffin formed the oil phase of the emulsion. In the formulation of emulgel, ethanol was used as a cosolvent for the drug, while propylene glycol was used as a cosolvent as well as humectant. Butylated hydroxytoluene (BHT) and ethylenediamine tetra acetic acid (EDTA) were added as the antioxidant and chelating agent, respectively. For their preservative action, methyl paraben and propyl paraben were added. Triethanolamine was used to adjust the $\mathrm{pH}$ of the formulation between 6.3 and 6.5 .

\section{Drug-excipient compatibility studies}

In the preparation of emulgel formulation, the drug and excipients may interact as they are in close contact with each other, which could result in instability of drug or the formulation. For this reason, preformulation studies regarding drug-excipient interaction are very critical in selecting appropriate excipients. Fourier-transform infra red (FTIR) spectroscopy was employed to ascertain the compatibility of the drug with various excipients used.

FTIR spectra of the individual drug and drug with each excipient were obtained using sodium chloride discs. The samples were mixed with heavy liquid paraffin and the applied between the sodium chloride discs. By using these discs in the FTIR spectrophotometer, the graphs were obtained, which were further studied for any change in peak i.e. shifting or disappearance of any peak with respect to peaks of the pure drug. The results of the study did not reveal any sign of incompatibility between the drug and the excipients used.

\section{Analytical method}

UV spectrophotometry was used to analyze the drug concentration in the formulations. The absorption maximum of the drug was found to be $\mathrm{pH}$ dependent. The absorption maxima of the drug were 
determined by dissolving the drug in different media and spectra were obtained using UV spectrophotometer. The absorption maxima $\left(\lambda_{\max }\right)$ of loratadine in the selected media are reported in Table 1.

Table 1. Absorption maxima of loratadine in selected media

\begin{tabular}{|c|c|c|}
\hline S. No. & Media & Absorption maxima $\left(\lambda_{\max }\right)$ \\
\hline 1. & $0.1 \mathrm{~N} \mathrm{HCl}$ & $277 \mathrm{~nm}$ \\
\hline 2. & Citro phosphate buffer $\mathrm{pH} 5.0$ & $267 \mathrm{~nm}$ \\
\hline 3. & Phosphate buffer $\mathrm{pH} 7.4$ & $248 \mathrm{~nm}$ \\
\hline
\end{tabular}

\section{Formulation and preparation of emulgels}

Preliminary studies. Prior to the preparation of emulgel formulations, preliminary experimental batches were formulated wherein their respective emulsions were prepared without the drug and, checked for their homogeneity and stability. The formulae for the preliminary study batches are reported in Tables 2-4. Batches C1-C7 represent the emulsions prepared with cetrimide, while, S1-S7 designate the emulsions containing sodium lauryl sulphate. Likewise, N1-N4 stand for emulsions prepared with Span 20 and Tween 20. The emulsion batches were formulated using the surfactants and auxiliary emulsifying agents in varying proportions, so as to achieve optimum product stability and consistency.

The following paragraph describes the procedure adopted for the preparation of the emulsions, employing different quantities of cetrimide, SLS and, Span 20 and Tween 20.

The oil phase of emulsion was prepared by dissolving the oil soluble surfactant and butylated hydroxy toluene (BHT) in light liquid paraffin. The aqueous phase was prepared by dissolving the water soluble surfactant in distilled water. Methyl paraben and propyl paraben were dissolved in propylene glycol. Propylene glycol solution was, then, dissolved in aqueous phase with constant stirring. Both, the oil phase and the aqueous phase, were separately heated to $60-70^{\circ}$. Next, the oil phase was added to the aqueous phase with constant homogenization. Thereafter, the emulsions were allowed to cool to room temperature.

Table 2. Composition of preliminary emulsion batches using cetrimide

\begin{tabular}{|c|c|c|c|c|c|c|c|c|}
\hline S. No. & Ingredients & C1 (g) & C2 (g) & C3 (g) & C4 (g) & C5 (g) & C6 (g) & C7 (g) \\
\hline 1. & $\begin{array}{c}\text { Liquid } \\
\text { paraffin(light) }\end{array}$ & 7.5 & 7.5 & 7.5 & 7.5 & 7.5 & 7.5 & 7.5 \\
\hline 2. & $\begin{array}{c}\text { Propylene } \\
\text { glycol }\end{array}$ & 5 & 5 & 5 & 5 & 5 & 5 & 5 \\
\hline 3. & Cetrimide & 0.15 & 0.15 & 0.15 & 0.15 & 0.15 & 0.5 & 0.3 \\
\hline 4. & $\begin{array}{c}\text { Glyceryl } \\
\text { monostearate }\end{array}$ & - & - & - & 1.5 & 1.5 & 1.5 & 1.5 \\
\hline 5. & Cetyl alcohol & - & 1.25 & 0.5 & 0.75 & 0.5 & 0.5 & 0.5 \\
\hline 6. & $\begin{array}{c}\text { Cetostearyl } \\
\text { alcohol }\end{array}$ & 1.25 & - & 0.75 & - & - & - & - \\
\hline 7. & Methyl paraben & 0.03 & 0.03 & 0.03 & 0.03 & 0.03 & 0.03 & 0.03 \\
\hline 8. & Propyl paraben & 0.01 & 0.01 & 0.01 & 0.01 & 0.01 & 0.01 & 0.01 \\
\hline 9. & $\begin{array}{c}\text { Distilled water } \\
\text { (q.s.) }\end{array}$ & 50 & 50 & 50 & 50 & 50 & 50 & 50 \\
\hline
\end{tabular}


Table 3. Composition of preliminary emulsion batches using sodium lauryl sulfate

\begin{tabular}{|c|c|c|c|c|c|c|c|c|}
\hline S. No. & Ingredients & S1 (g) & S2 (g) & S3 (g) & S4 (g) & S5 (g) & S6 (g) & S7 (g) \\
\hline 1. & $\begin{array}{c}\text { Liquid } \\
\text { paraffin(light) }\end{array}$ & 6.34 & 6.34 & 6.34 & 7.5 & 7.5 & 7.5 & 7.5 \\
\hline 2. & Propylene glycol & 5.64 & 5.64 & 5.64 & 5 & 5 & 5 & 5 \\
\hline 3. & $\begin{array}{c}\text { Sodium lauryl } \\
\text { sulfate }\end{array}$ & 1 & 1 & 1 & 1 & 1 & 1 & 1 \\
\hline 4. & $\begin{array}{c}\text { Glyceryl } \\
\text { monostearate }\end{array}$ & 2.5 & 2 & - & - & 1 & 1.5 & 1.75 \\
\hline 5. & Cetyl alcohol & - & 0.5 & 2.3 & - & - & - & 0.5 \\
\hline 6. & Cetostearyl alcohol & - & - & - & 1.25 & 1.25 & 0.75 & - \\
\hline 7. & Methyl paraben & 0.03 & 0.03 & 0.03 & 0.03 & 0.03 & 0.03 & 0.03 \\
\hline 8. & Propyl paraben & 0.01 & 0.01 & 0.01 & 0.01 & 0.01 & 0.01 & 0.01 \\
\hline 9. & $\begin{array}{c}\text { Distilled water } \\
\text { (q.s.) }\end{array}$ & 50 & 50 & 50 & 50 & 50 & 50 & 50 \\
\hline
\end{tabular}

Table 4. Composition of preliminary emulsion batches using Span 20 \& Tween 20

\begin{tabular}{|c|c|c|c|c|c|}
\hline S. No. & Ingredients & N1 $\mathbf{( g )}$ & $\mathbf{N 2} \mathbf{( g )}$ & $\mathbf{N 3} \mathbf{( g )}$ & $\mathbf{N 4} \mathbf{( g )}$ \\
\hline 1. & Liquid paraffin(light) & 7.5 & 7.5 & 7.5 & 7.5 \\
\hline 2. & Propylene glycol & 5 & 5 & 5 & 5 \\
\hline 3. & Span 20 & 1.35 & 2.1 & 1.35 & 2.1 \\
\hline 4. & Tween 20 & 1.65 & 0.9 & 1.65 & 0.9 \\
\hline 5. & Cetyl alcohol & 0.5 & 0.5 & - & - \\
\hline 6. & EDTA & 0.02 & 0.02 & 0.02 & 0.02 \\
\hline 7. & BHT & 0.02 & 0.02 & 0.02 & 0.02 \\
\hline 8. & Methyl paraben & 0.03 & 0.03 & 0.03 & 0.03 \\
\hline 9. & Propyl paraben & 0.01 & 0.01 & 0.01 & 0.01 \\
\hline 10. & Distilled water (q.s.) & 50 & 50 & 50 & 50 \\
\hline
\end{tabular}

Preparation of loratadine emulgels. The preliminary formulation studies were followed by the preparation of the final emulgel batches. Prior to this, the formulae for emulgel batches were selected on the basis of homogeneity and stability testing of the preliminary emulsion batches. As a result, formulations C7, S7 and N4 were selected owing to their good consistency and adequate stability. Henceforth, auxiliary emulsifying agents, glyceryl monostearate $(1.75 \%)$ and cetyl alcohol $(0.5 \%)$ were used in the formulation of emulgel with SLS (as shown in Table 5). Glyceryl monostearate (1.5\%) and cetyl alcohol $(0.5 \%)$ were used in the formulation of emulgel with cetrimide (refer to Table 6). Similarly, for the preparation of emulgel with non-ionic surfactants, Span 20 and Tween 20 were employed in the concentrations of $2.1 \%$ and $0.9 \%$, respectively (given in Table 7).

The emulgels were prepared by the following procedure:

To begin with, the emulsion part of the emulgel was prepared. The oil phase of emulsion was prepared by dissolving oil soluble surfactant and BHT in light liquid paraffin. In order to prepare the aqueous phase, EDTA was dissolved in distilled water. Subsequently, the water soluble surfactant was added to the solution and dissolved. Loratadine was dissolved in ethanol while methyl paraben and propyl paraben were dissolved in propylene glycol. Thereafter, ethanol and propylene glycol solutions were dissolved in aqueous phase with constant stirring. Both, the oil phase and aqueous phase were separately heated to $60-70^{\circ}$. Oil 
phase was added to aqueous phase with constant homogenization, until it cooled to room temperature. The gel phase was prepared by dispersing carbopol 940 in distilled water, which was kept overnight, followed by stirring at a moderate and constant speed. The $\mathrm{pH}$ of gel base was adjusted to 6-7 using triethanolamine. The emulsion prepared by this method was gellified in gel base in the ratio $1: 1$, with gentle stirring. In this manner, emulgels were obtained.

Table 5. Composition of emulgels formulated with sodium lauryl sulfate

\begin{tabular}{|c|c|c|c|c|}
\hline S. No. & Ingredients & S8 (g) & S9 (g) & S10 (g) \\
\hline 1. & Loratadine & 1 & 1 & 1 \\
\hline 2. & Ethanol & 10 & 10 & 20 \\
\hline 3. & Liquid paraffin (light) & 5 & 5 & 5 \\
\hline 4. & Propylene glycol & 5 & 5 & 5 \\
\hline 5. & Sodium lauryl sulfate & 1 & 1 & 1 \\
\hline 6. & Glyceryl monostearate & 1.75 & 1.75 & 1.75 \\
\hline 7. & Cetyl alcohol & 0.5 & 0.5 & 0.5 \\
\hline 8. & Methyl paraben & 0.03 & 0.03 & 0.03 \\
\hline 9. & Propyl paraben & 0.01 & 0.01 & 0.01 \\
\hline 10. & BHT & 0.02 & 0.02 & 0.02 \\
\hline 11. & EDTA & 0.02 & 0.02 & 0.02 \\
\hline 12. & Triethanolamine & q.s. & q.s. & q.s. \\
\hline 13. & Carbopol 940 & 0.25 & 0.5 & 0.75 \\
\hline 14. & Distilled water (q.s.) & 100 & 100 & 100 \\
\hline
\end{tabular}

Table 6. Composition of emulgels formulated with cetrimide

\begin{tabular}{|c|c|c|c|c|}
\hline S. No. & Ingredients & C8 (g) & C9 (g) & C10 (g) \\
\hline 1. & Loratadine & 1 & 1 & 1 \\
\hline 2. & Ethanol & 10 & 20 & 20 \\
\hline 3. & Liquid paraffin(light) & 5 & 5 & 5 \\
\hline 4. & Propylene glycol & 5 & 5 & 5 \\
\hline 5. & Glycerol & 3 & 3 & 3 \\
\hline 6. & Cetrimide & 0.3 & 0.3 & 0.3 \\
\hline 7. & Glyceryl monostearate & 1.75 & 1.75 & 1.75 \\
\hline 8. & Cetyl alcohol & 0.5 & 0.5 & 0.5 \\
\hline 9. & Methyl paraben & 0.03 & 0.03 & 0.03 \\
\hline 10. & Propyl paraben & 0.01 & 0.01 & 0.01 \\
\hline 11. & BHT & 0.02 & 0.02 & 0.02 \\
\hline 12. & EDTA & 0.02 & 0.02 & 0.02 \\
\hline 13. & Triethanolamine & q.s. & q.s. & q.s. \\
\hline 14. & Carbopol 940 & 0.25 & 0.5 & 0.75 \\
\hline 15. & Distilled water (q.s.) & 100 & 100 & 100 \\
\hline
\end{tabular}


Table 7. Composition of emulgel formulated with Span 20 \& Tween 20

\begin{tabular}{|c|c|c|}
\hline S. No. & Ingredients & N5 (g) \\
\hline 1. & Loratadine & 1 \\
\hline 2. & Ethanol & 10 \\
\hline 3. & Liquid paraffin(light) & 5 \\
\hline 4. & Propylene glycol & 2.1 \\
\hline 5. & Span 20 & 0.9 \\
\hline 6. & Tween 20 & 0.03 \\
\hline 7. & Methyl paraben & 0.01 \\
\hline 8. & Propyl paraben & 0.02 \\
\hline 9. & BHT & 0.02 \\
\hline 10. & EDTA & 0.5 \\
\hline 11. & Carbopol 940 & q.s. \\
\hline 12. & Triethanolamine & 100 \\
\hline 13. & Distilled water (q.s.) & \\
\hline
\end{tabular}

\section{Characterization of emulgels}

The prepared emulgels were evaluated for the relevant physical parameters as described below.

Homogeneity study. The emulgels were visually inspected for color, homogeneity and consistency.

Determination of $\mathrm{pH}$. Emulgels $(1 \mathrm{~g})$ were accurately weighed and dispersed in $100 \mathrm{ml}$ of distilled water. The $\mathrm{pH}$ of the dispersion was measured using $\mathrm{pH}$ meter (Max Instruments Chandigarh, India), which was calibrated before each reading, with buffered solution at $\mathrm{pH} 4.0$ and 7.0.

Rheological studies. In the context of semisolid dosage forms, viscosity is of paramount importance. Hence, all the emulgels were checked for their viscosity using DV-1 Prime (Brookfield Engineering Laboratories, USA) viscometer, at $25^{\circ}$, at $12 \mathrm{rpm}$, using spindle $\mathrm{S} 64$.

Centrifugation study. Centrifugation study is a useful means to check the stability of the prepared emulgels. These studies were performed one week after the preparation of emulgels. Centrifugation was carried out using Minicentrifuge at 3000 rpm for duration of 30 minutes.

Microscopic evaluation. Globule size of the prepared emulgels was determined by optical microscopy. A compound microscope was used for this purpose and the globules were observed under 40x magnification. Prior to observation, the eye-piece micrometer was calibrated with a stage micrometer and calibration factor was obtained. Subsequently, mean globule size was calculated [16].

Temperature swing test. Temperature swing test gives the formulator an idea about the stability of the formulation in extreme temperature conditions. Therefore, this test is frequently employed in the evaluation of topical semisolid dosage forms. For the purpose of this test, the formulations were subjected to freeze and thaw cycles. One cycle comprised of $8 \mathrm{~h}$ storage at $-4^{\circ}$ and another was carried out for $16 \mathrm{~h}$ at $40^{\circ}$. This was performed for 2 days. The formulations were visually inspected the end of the test to ascertain their stability [13].

Drug content determination. In order to determine the drug content of the emulgels, two different methods were developed and validated in the laboratory: one for the emulgels containing cationic and anionic surfactant and, another for that formulated with non-ionic surfactants. The emulgel formulated with Span 20 and Tween 20 was analyzed using $0.1 \mathrm{M} \mathrm{HCl}$ as the solvent. Accurately weighed, $1 \mathrm{~g}$ of 
prepared emulgel was dispersed in $0.1 \mathrm{M} \mathrm{HCl}$ solution. Then, this dispersion was further diluted with $0.1 \mathrm{M} \mathrm{HCl}$ and analyzed using UV spectrophotometer.

For drug content determination of emulgels prepared with SLS and cetrimide, the following method was employed. In the first step, accurately weighed $500 \mathrm{mg}$ emulgel was dissolved in dichloromethane and shaken for $2 \mathrm{~h}$. The solution was filtered, and transferred to watch glass. By heating the solution on watch glass, dichloromethane was evaporated, leaving behind the residue. To the residue, $10 \mathrm{ml}$ of methanol was added and, this was further diluted with phosphate buffer pH 7.4 and analyzed using UV spectrophotometer.

Stability studies. Stability studies of the prepared emulgels were carried out at two different temperature conditions, that is, at $4^{\circ} \pm 2^{\circ}$ and $25^{\circ} \pm 2^{\circ}$ for 3 months. To perform these studies, the formulations were packed in $15 \mathrm{ml}$ glass vials. The selected formulations were analyzed for consistency, drug content and $\mathrm{pH}$, at fortnightly intervals.

Spreadability study. Spreadability is an important criterion for evaluating a topical formulation, since it determines the ease of its application. Spreadability is the term expressed to denote the extent of area over which the formulation readily spreads upon application to skin or in the affected part. Thus, it also affects the therapeutic benefit derived from the formulation. The spreadability of the emulgels was measured by an apparatus suggested by Mutimer [17]. It consists of wooden block, attached to pulley at one end. This property is determined upon the basis of 'Slip' and 'Drag' characteristics of the emulgel.

Spreadability is expressed in terms of time in seconds taken by two slides to slip off from emulgel, placed in between the slides under the direction of certain load. The lesser the time taken for separation of two slides, better the spreadability. It is calculated by using the formula given in equation 1 :

$$
\mathrm{S}=\mathrm{M} \times \mathrm{L} / \mathrm{T}
$$

where $M=$ weight tied to upper slide $(\mathrm{g}), \mathrm{L}=$ length of glass slides $(\mathrm{cm}), T=$ time taken to separate the slides (s) [18].

An excess of emulgel (about $2 \mathrm{~g}$ ) was applied on the ground slide. Then, the emulgel was sandwiched between the ground slide and the second slide (upper slide), having the same dimensions as that of fixed ground slide. The upper slide was provided with a hook. Some weight was placed on the top of two slides for 5 minutes to expel air and to provide uniform film of the emulgel between the two slides. A known weight was placed in the pan attached to the pulley with the help of hook. The time (in seconds) taken by the upper slide to cover a distance $5 \mathrm{~cm}$ was noted [12].

Ex vivo drug release study. Ex vivo drug release study of the prepared emulgels (C10, S10 and N5) was performed using male albino rats, weighing $180-200 \mathrm{~g}$. The rats were sacrificed by cervical dislocation and their skin was removed and shaved. Skin explants with a contact area of $1.53 \mathrm{~cm}^{2}$ were mounted on receptor compartment of the Franz diffusion cells. The receptor compartment was filled with citro phosphate buffer ( $\mathrm{pH}$ 5.0). Thereafter, the emulgel was applied on the outer skin surface through donor compartment. To maintain sink conditions, the medium in receptor compartment was stirred using magnetic stirrer at $600 \mathrm{rpm}$. Samples $(3 \mathrm{ml})$ were withdrawn from the receptor compartment and replenished with an equal volume of fresh medium at hourly intervals, up to 8 hours. The amount of drug released was determined by analyzing the samples spectrophotometrically. The study was performed in triplicate for each formulation. Thereafter, the mean and standard deviation values were calculated. 
Drug release kinetics studies. Drug release kinetics was investigated by fitting the data obtained from ex vivo drug release studies into various drug release kinetics models. For the purpose of this study, zero order, first order and Higuchi plots were prepared.

The zero order plots were prepared by plotting cumulative percent drug permeated on vertical axis against time (in hours) on horizontal axis. In order to study the formulations for first order kinetics, log cumulative percent drug remaining was plotted versus time (in hours). Furthermore, cumulative percent drug permeated taken on $\mathrm{Y}$-axis versus square root of time (in hours) on $\mathrm{X}$-axis gave the Higuchi plots. The most appropriate model was selected based upon goodness-of fit test. The plot which resulted in maximum value of correlation coefficient, $r^{2}$, was considered to be the most appropriate for the given formulation $[19,20]$.

Skin irritation study. Skin irritation study is a prerequisite for any topical formulation as it enables to determine its skin irritation potential. Prior to conducting the animal studies, approval was obtained from the Institutional Animal Ethical Committee, MMU, Mullana-Ambala (MMCP/IEC/11/10). All the animals were treated according to the guidelines provided by the Institutional Animal Ethical Committee. The skin irritation studies were performed on guinea pigs. The dorsal skin region of the guinea pigs was shaved using clipper one day before study. The animals were treated with test formulations for 3 days and the treated skin was examined visually for erythema and edema. The observations were compared with that of the untreated skin, which was taken as control [19].

In vivo anti-allergic activity. The test for anti-allergic activity was performed on male albino rats. $500 \mathrm{mg}$ of the selected emulgels was applied to the dorsal skin of the animals and the formulation was evenly spread until it was completely absorbed. The animals $(n=6)$ were divided into different groups and were given the following treatment: Group I was treated with formulation S10, Group II was treated with formulation C10, Group III with formulation N5, Group IV was treated with histamine alone, while Group V served as the control and was, therefore, left untreated. Hence, groups I, II and III received treatment with the prepared emulgels. Subsequent to the application of the formulations, $50 \mu \mathrm{l}$ of histamine hydrochloride solution $(0.1 \mu \mathrm{g} / \mathrm{ml}$ in a solution of water/glycerol: $50 / 50 \mathrm{v} / \mathrm{v})$ was injected into the upper layers of the dorsal skin of each of group I, II, III and IV. The effect of histamine-induced cutaneous reactions was noted by visual inspection at definite intervals, i.e. 15, 30 and 60 minutes. The observed responses were evaluated with respect to those of groups IV and V [20].

Statistical analysis. Statistical analysis was performed using Student's paired t-test using Graphpad Version 2.01, San Diego, CA. The data was considered significant at $(p<0.05)$.

\section{Results and Discussion}

Physical evaluation of emulgels

Homogeneity of a topical formulation is gives the formulator an idea about the consistency, stability and elegance of the final product. Incorporation of propylene glycol as a humectant and Carbopol 940 as the gelling agent contributed towards the homogeneity of the emulgels.

The findings of this study formed the basis for selecting the composition of the final study batches. The results of homogeneity study performed on preliminary emulsion batches are shown in Table 8-10. The compositions which gave stable and homogeneous emulsions were taken up for formulation into final emulgels. Further, the emulgels so prepared were also tested for their homogeneity. The results are 
reported in Table 11. All the formulations were white in color. It is evident from the observations of this study that C10, S10 and N5 exhibited adequate homogeneity and were, therefore, subject to further evaluation.

Table 8. Observation table for preliminary batches of emulsion with cetrimide

\begin{tabular}{|c|c|c|c|c|c|c|c|c|}
\hline \multirow{2}{*}{ S. No. } & \multirow{2}{*}{ Test } & \multicolumn{9}{|c|}{ Formulation code } & C6 & C7 \\
\cline { 3 - 8 } & C1 & C2 & C3 & C4 & C5 & C6 \\
1. & Homogeneity & $\begin{array}{c}\text { Good } \\
\text { consistency }\end{array}$ & $\begin{array}{c}\text { Foamy } \\
\text { appearance, } \\
\text { good } \\
\text { consistency }\end{array}$ & $\begin{array}{c}\text { Foamy } \\
\text { appearance, } \\
\text { good } \\
\text { consistency }\end{array}$ & $\begin{array}{c}\text { Too } \\
\text { viscous, } \\
\text { clumping } \\
\text { observed }\end{array}$ & $\begin{array}{c}\text { Good } \\
\text { appearance } \\
\text { but too } \\
\text { viscous }\end{array}$ & $\begin{array}{c}\text { Good } \\
\text { consistency } \\
\text { and elegant } \\
\text { appearance }\end{array}$ & $\begin{array}{c}\text { Good } \\
\text { consistency } \\
\text { and elegant } \\
\text { appearance }\end{array}$ \\
\hline 2. & Stability* & Stable & Stable & Stable & - & - & Stable & Stable \\
\hline
\end{tabular}

*performed using Minicentrifuge at $7000 \mathrm{rpm}$ for $5 \mathrm{~min}$

Table 9. Observation table for preliminary batches of emulsion with SLS

\begin{tabular}{|c|c|c|c|c|c|c|c|c|}
\hline \multirow{2}{*}{ S. No. } & \multirow{2}{*}{ Test } & \multicolumn{7}{|c|}{ Formulation code } \\
\hline & & S1 & S2 & S3 & S4 & S5 & S6 & S7 \\
\hline 1. & Homogeneity & $\begin{array}{l}\text { Very } \\
\text { thick }\end{array}$ & $\begin{array}{c}\text { Good } \\
\text { consistency }\end{array}$ & $\begin{array}{l}\text { Undesirable due } \\
\text { to excessive } \\
\text { foaming }\end{array}$ & $\begin{array}{c}\text { Phase } \\
\text { separation } \\
\text { observed }\end{array}$ & $\begin{array}{c}\text { Poor } \\
\text { consistency }\end{array}$ & Cracking observed & $\begin{array}{c}\text { Good } \\
\text { consistency }\end{array}$ \\
\hline 2. & Stability* & Stable & Stable & - & Unstable & Stable & Unstable & Stable \\
\hline
\end{tabular}

*performed using Minicentrifuge at $7000 \mathrm{rpm}$ for $5 \mathrm{~min}$

Table 10. Observation table for preliminary batches of emulsion with Span 20 and Tween 20

\begin{tabular}{|c|c|c|c|c|c|}
\hline \multirow{2}{*}{ S. No. } & \multirow{2}{*}{ Test } & \multicolumn{4}{|c|}{ Formulation code } \\
\hline & & N1 & N2 & N3 & N4 \\
\hline 1. & Homogeneity & $\begin{array}{c}\text { Phase separation } \\
\text { within } 1 \mathrm{~h} \text { of } \\
\text { preparation }\end{array}$ & Poor consistency & Too viscous & Good consistency \\
\hline 2. & Stability* & Unstable & Unstable & Stable & Stable \\
\hline
\end{tabular}

*performed using Minicentrifuge at $7000 \mathrm{rpm}$ for $5 \mathrm{~min}$

Table 11. Observation table for selected batches of emulgels

\begin{tabular}{|c|c|c|c|c|c|c|c|}
\hline \multirow{2}{*}{ Observation } & \multicolumn{7}{|c|}{ Formulation code } \\
\hline & C8 & C9 & C10 & S8 & S9 & S10 & N5 \\
\hline Homogeneity study & $\begin{array}{l}\text { Unstable, } \\
\text { precipitation of } \\
\text { drug observed }\end{array}$ & $\begin{array}{l}\text { Stable but poor } \\
\text { consistency }\end{array}$ & $\begin{array}{c}\text { Good } \\
\text { consistency }\end{array}$ & $\begin{array}{l}\text { Very Low } \\
\text { viscosity }\end{array}$ & Low viscosity & $\begin{array}{c}\text { Good } \\
\text { consistency }\end{array}$ & $\begin{array}{c}\text { Good } \\
\text { consistency }\end{array}$ \\
\hline
\end{tabular}

Thus, formulations C10, S10 and N5 were tested for their physical properties like pH, spreadability, drug content, average globule size and effect of centrifugation.

The $\mathrm{pH}$ was determined at room temperature using digital $\mathrm{pH}$ meter. These values were well within the $\mathrm{pH}$ range of the human skin. This was achieved by the incorporation of triethanolamine $[21,22]$.

When subject to centrifugation, the emulgels did not show any sign of phase separation or change in the appearance. This implies that the prepared formulations are stable to mechanical stress. As reported in the literature too, formulations showing no phase separation are considered to be thermodynamically stable systems $[23,24]$.

Temperature swing test. Temperature swing test was performed in B.O.D incubator by storing the formulations, initially, at $-4{ }^{\circ} \mathrm{C}$ for $8 \mathrm{~h}$ and, later, at $40^{\circ} \mathrm{C}$ for the next $16 \mathrm{~h}$. The emulgels did not show any 
sign of inconsistency at the end of the temperature swing test. This further strengthens the outcome of centrifugation study, suggesting optimum stability of the selected formulations [23].

The drug content of all the formulations was found to be within the desired range.

Globule size/average droplet size is also considered to be an important factor in context of physical stability of the product $[25,26]$. Therefore, mean globule size was calculated for the prepared emulgels. Mean globule size is affected by a number of process and formulation variables. Since, our study focused on the effect of formulation variables, the findings of average globule size determination may be correlated with the surfactants used in the formulations. As given in literature, incorporation of non-ionic surfactants tends to lower the droplet size in the emulsions stabilized by acrylate polymers [22].

Formulation N5, prepared with non-ionic surfactants, had the lowest average globule diameter, which supports the findings cited in the literature.

The results are tabulated in the Table 12.

Table 12. Observation table for physical evaluation of selected emulgels

\begin{tabular}{|c|c|c|c|c|c|c|}
\hline S. No. & $\begin{array}{c}\text { Formulation } \\
\text { Code* }\end{array}$ & $\mathbf{p H}$ & $\begin{array}{c}\text { Spreadability } \\
(\mathbf{g . c m} / \mathbf{s})\end{array}$ & $\begin{array}{c}\text { Drug content } \\
\mathbf{( \% )}\end{array}$ & $\begin{array}{c}\text { Average } \\
\text { globule size } \\
(\boldsymbol{\mu} \mathbf{m})\end{array}$ & $\begin{array}{c}\text { Centrifugation } \\
\text { study }\end{array}$ \\
\hline 1. & C10 & $6.63 \pm 0.015$ & $13.32 \pm 0.759$ & $102.62 \pm 1.63$ & 2.32 & Stable \\
\hline 2. & S10 & $6.67 \pm 0.03$ & $18.84 \pm 1.58$ & $97.61 \pm 1.24$ & 1.82 & Stable \\
\hline 3. & N5 & $6.81 \pm 0.02$ & $20.25 \pm 1.403$ & $95.42 \pm 0.56$ & 0.875 & Stable \\
\hline
\end{tabular}

*C10: emulgel containing cetrimide; S10: emulgel containing SLS; N5: emulgel containing Tween 20 \& Span 20

Rheological study. Viscosity has profound significance with respect to the performance of topical products. Product characteristics, such as spreadability, ease of application, drug release and stability are closely linked to the viscosity of the formulation. Formulation variables, viz. gelling agent, surfactant, auxiliary emulsifiying agent, cosolvent and oil phase influence the rheological properties of the formulation. The results of viscosity determination are reported in Table 13. As evident, the viscosity of the prepared emulgels followed the order: $\mathrm{N} 5>\mathrm{C} 10>\mathrm{S} 10$.

Table 13. Observation table for viscosity measurement

\begin{tabular}{|c|c|c|c|c|}
\hline S. No. & Formulation Code* & Spindle used & Rpm & Viscosity** (cps) \\
\hline 1. & C10 & S64 & 12 & $43404 \pm 13.5$ \\
\hline 2. & S10 & S64 & 12 & $42391 \pm 56.66$ \\
\hline 3. & N5 & S64 & 12 & $44443 \pm 42.55$ \\
\hline
\end{tabular}

*C10: emulgel containing cetrimide; S10: emulgel containing SLS; N5: emulgel containing Tween 20 \& Span 20

** Mean of triplicate reading

Generally, the viscosity of a formulation increases with the increase in the concentration of the gelling agent [13]. Conversely, N5 was found to be the most viscous formulation, despite the low concentration of Carbopol 940. On the other hand, El-Megrab et al. report that the presence of alcohol in a formulation decreases its viscosity [27]. Formulations C10 and S10 contain twice the amount of alcohol as compared to N5. 
Moreover, it has also been mentioned in the literature that non-ionic surfactants increase the yield stress and viscosity of the emulsions stabilized using acrylates [22].

In view of the foregoing facts, the presence of non-ionic surfactants in N5 and a greater percentage of alcohol in C10 and S10 explains the observed order of viscosity in the emulgels. It may also be added that the inclusion of glycerol (3\%) in C10 led to a more viscous formulation than S10.

Stability study. Stability study was performed with the view to ascertain that the prepared formulations retain their physicochemical and therapeutic attributes. No significant change was observed in the physical appearance, consistency, percentage drug content and $\mathrm{pH}$ of any emulgel, throughout the period of storage. Thence, it was concluded that all the three types of surfactants, namely, cetrimide, SLS and, Span 20 and Tween 20 resulted in equally stable formulations. The observations for percent drug content and $\mathrm{pH}$ determination are tabulated in Tables 14(a) and (b), respectively.

Table 14(a). Observation table for stability study (Percent drug content)

\begin{tabular}{|c|c|c|l|c|c|}
\hline S. No. & $\begin{array}{c}\text { Temperature } \\
\text { Condition }\left({ }^{\circ} \mathbf{C}\right)\end{array}$ & $\begin{array}{c}\text { Time period } \\
\text { (days) }\end{array}$ & $\mathbf{C 1 0}$ & S10 & N5 \\
\hline 1. & 4 & 15 & $102.04 \pm 1.11$ & $97.24 \pm 0.50$ & $95.39 \pm 1.26$ \\
\hline 2. & 4 & 30 & $101.88 \pm 1.63$ & $97.27 \pm 0.81$ & $95.09 \pm 1.80$ \\
\hline 3. & 4 & 45 & $102.28 \pm 0.99$ & $97.2 \pm 0.58$ & $95.22 \pm 1.08$ \\
\hline 4. & 4 & 60 & $102.20 \pm 1.61$ & $96.70 \pm 1.41$ & $94.89 \pm 0.785$ \\
\hline 5. & 4 & 75 & $102.04 \pm 0.99$ & $97.27 \pm 0.63$ & $95.03 \pm 0.93$ \\
\hline 6. & 4 & 90 & $100.81 \pm 1.44$ & $97.34 \pm 1.43$ & $95.02 \pm 0.924$ \\
\hline 7. & 25 & 15 & $102.61 \pm 0.75$ & $97.23 \pm 0.82$ & $95.61 \pm 1.08$ \\
\hline 8. & 25 & 30 & $102.2 \pm 0.89$ & $97.41 \pm 0.47$ & $95.35 \pm 1.08$ \\
\hline 9. & 25 & 45 & $102.37 \pm 0.38$ & $97.27 \pm 0.63$ & $95.61 \pm 1.33$ \\
\hline 10. & 25 & 60 & $101.06 \pm 0.62$ & $97.23 \pm 1.05$ & $95.55 \pm 1.57$ \\
\hline 11. & 25 & 75 & $102.20 \pm 1.61$ & $97.34 \pm 0.75$ & $95.42 \pm 0.89$ \\
\hline 12. & 25 & 90 & $100.81 \pm 1.44$ & $97.16 \pm 0.96$ & $95.22 \pm 0.986$ \\
\hline
\end{tabular}

*Mean of triplicate reading

Table 14(b). Observation table for stability study (pH determination)

\begin{tabular}{|c|c|c|c|c|c|}
\hline S. No. & $\begin{array}{c}\text { Temperature } \\
\text { Condition }\left({ }^{\circ} \mathbf{C}\right)\end{array}$ & $\begin{array}{c}\text { Time period } \\
\text { (days) }\end{array}$ & $\mathbf{C 1 0}$ & S10 & N5 \\
\hline 1. & 4 & 15 & $6.62 \pm 0.01$ & $6.66 \pm 0.005$ & $6.82 \pm 0.01$ \\
\hline 2. & 4 & 30 & $6.62 \pm 0.01$ & $6.66 \pm 0.01$ & $6.82 \pm 0.02$ \\
\hline 3. & 4 & 45 & $6.62 \pm 0.015$ & $6.67 \pm 0.005$ & $6.82 \pm 0.015$ \\
\hline 4. & 4 & 60 & $6.64 \pm 0.01$ & $6.67 \pm 0.01$ & $6.85 \pm 0.015$ \\
\hline 5. & 4 & 75 & $6.63 \pm 0.015$ & $6.65 \pm 0.01$ & $6.84 \pm 0.015$ \\
\hline 6. & 4 & 90 & $6.64 \pm 0.015$ & $6.65 \pm 0.01$ & $6.82 \pm 0.017$ \\
\hline 7. & 25 & 15 & $6.64 \pm 0.005$ & $6.68 \pm 0.005$ & $6.81 \pm 0.005$ \\
\hline 8. & 25 & 30 & $6.63 \pm 0.005$ & $6.67 \pm 0.011$ & $6.82 \pm 0.1$ \\
\hline 9. & 25 & 45 & $6.64 \pm 0.005$ & $6.67 \pm 0.01$ & $6.84 \pm 0.015$ \\
\hline 10. & 25 & 60 & $6.63 \pm 0.005$ & $6.68 \pm 0.01$ & $6.83 \pm 0.1$ \\
\hline 11. & 25 & 75 & $6.61 \pm 0.01$ & $6.69 \pm 0.005$ & $6.83 \pm 0.02$ \\
\hline 12. & 25 & 90 & $6.62 \pm 0.01$ & $6.68 \pm 0.02$ & $6.83 \pm 0.005$ \\
\hline
\end{tabular}

*Mean of triplicate reading

Spreadability study. Conventionally, spreadability of a formulation is inversely related to its viscosity [28]. However, in our study the outcomes of the spreadability testing differ from the general argument. This observation may be explained by the globule size of the respective formulations. It was found that 
emulgel N5 had the least average globule size, followed by S10 and C10. It has been reported that lower globule size of emulsion phase results in better spreadability of the product [22]. Hence, spreadability of the prepared emulgels decreased in the order: $\mathrm{N} 5>\mathrm{S} 10>\mathrm{C} 10$.

Ex vivo drug release study. The ex vivo drug release study was performed on male albino rats. With the view to analyze the drug release from the three emulgels, cumulative amount of drug released was plotted against time. Figure 1 depicts the drug release obtained from the emulgels for a period of 8 hours. Amount of drug release was found to decrease in the following order: $\mathrm{C} 10>\mathrm{S} 10>\mathrm{N} 5$.

The results obtained for ex vivo drug release study can be explained by taking into account the various factors that are known to influence the availability of the drug from a topical formulation. These factors include viscosity, mean droplet size, gelling agent, auxiliary emulsifying agent, presence of cosolvents and surfactants.

It is well reported in literature that viscosity of a formulation strongly affects the release of drug [29]. As stated earlier, an increase in viscosity decreases the drug release. However, this was not the case in our study, indicating that other factors contribute more strongly towards drug release.

Mahdi et al. have reported the effect of globule size on drug release. Their findings indicate that lower globule size results in higher release [30]. On the contrary, in our study, formulation C10 with the largest globule size showed maximum drug release.

Capakova et al. emphasized the importance of selecting appropriate gelling agent and its concentration for optimum drug availability. Their group evaluated the effect of varying concentration of Carbopol 980 upon the release of loratadine from hydrogels. As per their report, increasing the concentration of Carbopol 980 led to lower drug release [29]. When compared to our findings, formulation C10, containing greater amount of gelling agent gave maximum release of the drug. This suggests that in case of emulgels, gelling agent concentration does not play a dominant role in controlling drug release.

In relation to auxiliary emulsifying agents, literature reports that the presence of glyceryl monostearate in a formulation, increases drug release significantly [31]. In our study too, drug release was found to be highest from $\mathrm{C} 10$, followed by S10, both containing glyceryl monostearate as the auxiliary emulsifying agent.

From the perspective of cosolvents, ethanol and propylene glycol have been used to enhance solubilization of loratadine. Song et al state that propylene glycol promotes the uptake of the drug into the skin by modifying the driving force for its diffusion [32]. On the other hand, the solubilizing property of ethanol facilitates drug release from the formulation [27]. Further, ethanol also decreases the viscosity of carbopol gel, thereby, affecting drug release [21].

In the present study, formulation $\mathrm{C} 10$ and S10, contain higher concentration of ethanol, as compared to N5. This accounts for greater drug release from the former two emulgels.

Form the discussion, it may be inferred that ethanol and glyceryl monostearate were responsible for greater drug release from C10 and S10. Since, both the ingredients were present in equal amounts in the two formulations, they can be assumed to have contributed equally towards release of the drug.

Accordingly, the above argument leads to the conclusion that the type of surfactant plays a major role in promoting drug release. In the present investigation, effect of different types of surfactants i.e. cationic, anionic and non-ionic, has been compared. 
A higher drug release was obtained from formulation C10 as compared to S10, signifying cetrimide's ability to produce greater reduction in interfacial tension between the oily phase of the emulsion and aqueous layer of the dispersion medium, thereby, facilitating the penetration of the dissolution medium into the emulgels. This permits greater drug release from the formulation [33].

Drug release kinetics study. The data obtained from ex vivo drug release study was fitted into various kinetic models and it was processed to obtain the relevant plots i.e. zero order, first order and Higuchi plot. The $r^{2}$ values obtained for the three emulgels for the various plots are listed in Table 15.

The $r^{2}$ values clearly suggest that the drug release from the all the formulations is concentration independent on account of the highest linearity for zero order plots.

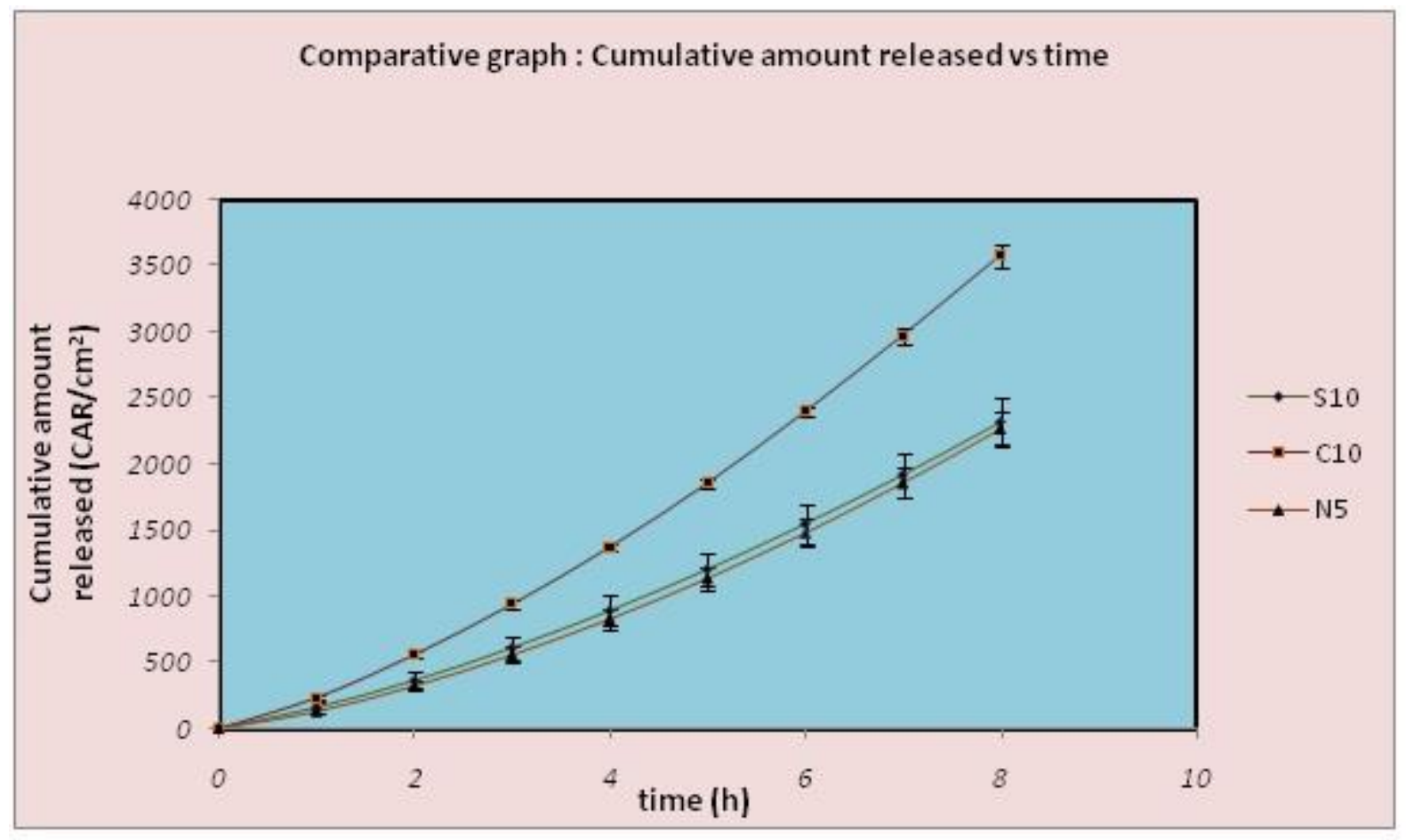

Figure 1. Graph showing comparison between cumulative amount released $(\mu \mathrm{g})$ versus time $(\mathrm{h})$ for different formulations

Table 15. $r^{2}$ values obtained for various plots

\begin{tabular}{|c|c|c|c|c|}
\hline S. No. & \multirow{2}{*}{$\begin{array}{c}\text { Formulation } \\
\text { Code* }\end{array}$} & \multicolumn{3}{|c|}{$r^{2}$ values } \\
\cline { 3 - 5 } & Zero order & First order & Higuchi plot \\
\hline 1. & C10 & 0.983 & 0.9753 & 0.8356 \\
\hline 2. & S10 & 0.9833 & 0.9787 & 0.837 \\
\hline 3. & N5 & 0.9776 & 0.9725 & 0.8221 \\
\hline
\end{tabular}

*C10: emulgel containing cetrimide; S10: emulgel containing SLS; N5: emulgel containing Tween 20 \& Span 20

Skin irritation test. The results of skin irritation test were assessed on the basis of Draize-FHSA (Federal Hazardous Substance Act) scoring system [11] and the scores obtained for each formulation are given in table 16.

Since, there was no sign of erythema or edema on the skin of the guinea pigs treated with the test formulations, a score of zero was assigned to each, with regard to skin irritation potential. Hence, all the emulgel formulations passed the skin irritation test. 
Table 16. Scores for erythema and edema produced in guinea pigs

\begin{tabular}{|c|c|c|c|}
\hline \multirow{2}{*}{ S. No. } & Formulation code* & \multicolumn{2}{|c|}{ Score } \\
\cline { 3 - 4 } & & $\mathbf{2 4} \mathbf{~}$ & $\mathbf{7 2} \mathbf{~}$ \\
\hline 1. & C10 & 0 & 0 \\
\hline 2. & S10 & 0 & 0 \\
\hline 3. & N5 & 0 & 0 \\
\hline
\end{tabular}

*C10: emulgel containing cetrimide; S10: emulgel containing SLS; N5: emulgel containing Tween 20 \& Span 20

In vivo antiallergic activity. Skin testing for immediate type 1 hypersensitivity, prick and intracutaneous techniques were performed. This test consists of introduction of allergen extract or histamine into the skin resulting in IgE mediated allergic response, characterized by immediate wheal and flare reaction, due to activation of mast cells releasing vasoactive agents, which cause both, extravasation and vasodilation. The reactions are assessed by the degree of redness and swelling and the size of the wheal produced.

To evaluate the efficacy of the tested formulations, the potential irritation due to the cutaneous reactions induced by histamine injection on the dorsal surface of the rats was estimated. The visual examination of skin, 60 minutes after the administration of the developed formulations, revealed that the symptoms of hypersensitivity i.e. redness and itching, were absent in groups I, II and III. This indicates that loratadine emulgels were effective in alleviating the symptoms of skin allergy.

\section{Conclusions}

Topical drug delivery constitutes a major part of the therapy for skin diseases or disorders. Of late, topical drug delivery systems have assumed even greater importance owing to their localized action and lesser plausibility of systemic toxicity. In the recent years, emulgels have been explored as an alternative to conventional topical formulations to deliver several topical agents.

In the present study, it was attempted to incorporate loratadine into emulgel bases, using anionic, cationic and non-ionic surface-active agents. The emulgels were successfully prepared and exhibited optimum physical characteristics. All the three surfactants were found to produce equally stable formulations. Loratadine release from emulgels was found to be influenced by the interactions of the drug with surfactants, auxiliary emulsifying agents and cosolvents used in the formulation. These interactions affect the partitioning of the drug between the aqueous and oily phase of the formulation. The ex vivo drug release was found to be greatest for the emulgel formulated with cetrimide. Moreover, drug release from the formulations was independent of drug concentration. The formulations were non-irritant to the skin and effective in alleviating the symptoms of skin allergy.

Acknowledgements: The authors are highly grateful to Dr. Anroop Nair for his guidance and comments which were useful in designing the study. 


\section{References}

[1] P.S. Gelone, Remington: Science and Practice of Pharmacy, Wolters Kluwer Pvt. Ltd, New Delhi, India, 2006, p. 1615.

[2] A. Pentz, C. Els, O. Coetzee, R.J. Green, Current allergy and Clinical Immunology 27 (2014) 9-13. http://www.allergysa.org/journals/March2014/Anidealchildrenschest.pdf

[3] P. Small, Canadian Family Physician 35 (1989) 1859-1862. http://www.ncbi.nlm.nih.gov/pmc/articles/PMC2280873/pdf/canfamphys00163-0157.pdf

[4] Allergy statistics, http://www.aaaai.org/about-the-aaaai/newsroom/allergy-statistics.aspx (7th Aug, 2014).

[5] Allergies statistics and facts, http://www.healthline.com/health/allergies/statistics (7th Aug, 2014).

[6] Disease summaries: contact dermatitis, http://www.worldallergy.org/public/allergic diseases center/contactdermatitis/ (7th Aug, 2014).

[7] C. Motala, Current Allergy and Clinical Immunology 22 (2009) 71-74. http://reference.sabinet.co.za/webx/access/electronic journals/caci/caci v22 n2 a6.pdf

[8] P. Singh, M. Bajpai, S. Srivastava, Journal of Pharmaceutical Science and Research 3(2011) 11701175. http://www.jpsr.pharmainfo.in/Documents/Volumes/Vol3Issue04/ipsr\%2003110407.pdf

[9] V. Singla , S. Saini , B. Joshi, AC Rana, International Journal of Pharma and Biosciences 3(2012) 485-498.

http://www.ijpsr.com/V5I5/8\%20Vol.\%205,\%20Issue\%205,\%20May\%202014,IJPSR,\%20RE\%2011 98,\%20Paper\%208.pdf

[10] S.P. Stanos, Journal of Pain and Symptom Management 33(2007) 342-355. http://www.jpsmjournal.com/article/S0885-3924\%2807\%2900003-6/fulltext

[11] M. I. Mohamed, The AAPS Journal 6(2004) 1-7. http://www.ncbi.nlm.nih.gov/pmc/articles/PMC2751251/pdf/12248 2008 Article 6381.pdf

[12] R. Khullar, D. Kumar, N. Seth, S. Saini, Saudi Pharmaceutical Journal 20(2012) 63-67. http://www.ncbi.nlm.nih.gov/pmc/articles/PMC3745000/pdf/main.pdf

[13] M. Shahin, S. A. Hady, M. Hammad, N. Mortada, AAPS PharmSci Tech 12 (2012) 239-247. http://www.ncbi.nlm.nih.gov/pmc/articles/PMC3066381/pdf/12249 2011 Article 9583.pdf

[14] R. Khullar, S. Saini, N. Seth, A.C. Rana, International Journal of Pharmaceutical and Biological Sciences 1(2011) 117-127. http://www.ijpbs.com/ijpbsadmin/upload/ijpbs 50c82835a2df7.pdf

[15] Hatto Walch, US20030129209A1 (2003). http://www.google.com/patents/US20030129209

[16] A. Pasupathi, P. Palanisamy, B. Jayakar, R. M. Chandira, B. S. Venkateswarlu, Indian Journal of Research in Pharmacy and Biotechnology 1(2013) 95-105. http://www.ijrpb.com/current\%20issues/1/v1/ijrpb\%201 20\%20page\%2095-105.pdf

[17] M. N. Mutimer, C. Riffkin, J. A. Hill, M. E. Glickman, G. N. Cyr, Journal of the American Pharmaceutical Association 45(1956) 212-218.

[18] A. Jain, P. Deveda, N. Vyas, J. Chauhan, H. Khambete, S. Jain, International Journal of Pharmaceutical Research and Development 2(2011) 18-25. http://www.ijprd.com/Article No 257 Feb 11 03.html

[19] B. J. Saqib, M. I. Howard, Handbook of Cosmetic Science and Technology, Informa Healthcare, New York, USA, 2009, p. 471-474.

[20] D. L. M. Moretti, A. T. Peana, V. Sanna, International Journal of Pharm Tech Research 2(2010) 863-869.

http://sphinxsai.com/sphinxsaivol 2no.1/pharmtech vol 2no.1/PharmTech Vol 2No.1PDF/PT=1 31\%20\%28863-869\%29.pdf 
[21] C. M. Setty, S. R. Babubhai, I. B. Pathan, International Journal of Pharmacy and Pharmaceutical Sciences 2(2010) 70-73. http://www.ijppsjournal.com/Vol2Suppl1/337.pdf

[22] E Kettler, C.B. Muller, R. Klemp, M Hloucha, T. Doring, W. Von Rybinski, W. Richtering, Progress in colloid and polymer science: Surface and interfacial forces- From fundamentals to applications, Springer-Verlag Berlin Heidelberg, 2008, 91.

[23] M. S. Alam, M.S. Ali, N. Alam, M. I. Alam, T. Anwer, F. Imam, M. D. Ali, M. R. Siddiqui, M. Shamim, Journal of Applied Pharmaceutical Science 2(2012) 148-158. http://www.japsonline.com/admin/php/uploads/684 pdf.pdf

[24] J. D. Modi, J. K. Patel, International Journal of Pharmacy and Pharmaceutical Science Research 1(2011) 6-12. http://urpjournals.com/tocjnls/24 2.pdf

[25] T. Mahmood, N. Akhtar, S. Manickam, Journal of Nanobiotechnology 12(2014) 12-20. http://www.jnanobiotechnology.com/content/12/1/20

[26] T. Mahmood, N. Akhtar, The Scientific World Journal 2013(2013) 1-7. http://www.hindawi.com/journals/tswj/2013/153695/

[27] N. A. El-Megrab, H. M. El-Nahas, G. F. Balata, Saudi Pharmaceutical Journal, 14(2006) 155-162.

[28] M. Rao, G. Sukre, S. Aghav, M. Kumar, Journal of Pharmaceutics, 2013(2013) 1-9. http://www.hindawi.com/iournals/iphar/2013/501082/

[29] Z. Capkova, Z. Vitkova, M. Subova, Acta Facultatis Pharmaceuticae Universitatis Comenianae 52(2005) 73-78.

https://www.fpharm.uniba.sk/fileadmin/user upload/admin/Acta facultatis/Tomus LII/09 Capkova Z. - Vitkova Z. - Subova M.pdf

[30] E. S. Mahdi, A. M. Noor, M. A. Sattar, International Journal of Nanomedicine 6(2011) 2499-2512. http://www.ncbi.nlm.nih.gov/pmc/articles/PMC3439863/

[31] A.A.M. Lira, E. A. Sester, A. L. M. Carvalho, R. R. Strattmann, M. M. Albuquerque, A. G. Wanderley and D. P. Santana, AAPS PharmSci Tech 9(2008) 163-168.

http://www.ufpi.br/subsiteFiles/ppgcf/arquivos/files/1.pdf

[32] J. H. Song, S. C. Chin, Drug Development and Industrial Pharmacy 35(2009)897-903.

[33] D.A. El-Rhman, M. A. Nabarawi, S.A. Abdel Halim, D. A. Helal, Indian Streams Research Journal 4(2014)1-14. http://www.isri.net/UploadedData/4929.pdf 


\section{Appendix}

Table A1. Comparison of FTIR peaks of pure drug versus different excipients

\begin{tabular}{|c|c|c|c|c|c|c|c|}
\hline \multirow[b]{2}{*}{ S. No. } & \multicolumn{5}{|c|}{ Wavelength $\left(\mathrm{cm}^{-1}\right)$} & \multirow[b]{2}{*}{$\begin{array}{c}\text { Functional } \\
\text { groups }\end{array}$} & \multirow[b]{2}{*}{ Interference } \\
\hline & Pure drug & $\begin{array}{c}\text { Drug + } \\
\text { Cetrimide }\end{array}$ & $\begin{array}{c}\text { Drug+ } \\
\text { Cetyl } \\
\text { alcohol }\end{array}$ & $\begin{array}{l}\text { Drug + Glyceryl } \\
\text { monostearate }\end{array}$ & $\begin{array}{c}\text { Drug + } \\
\text { Sodium } \\
\text { lauryl } \\
\text { sulfate } \\
\end{array}$ & & \\
\hline 1. & 2960,2846 & 2909, 2774 & $\begin{array}{l}2963 \\
2845\end{array}$ & 2968,2850 & 2953,2864 & $\begin{array}{l}\text { (C-H) Aromatic } \\
\text { Stretch }\end{array}$ & No \\
\hline 2. & 1690 & 1692 & 1695 & 1710 & 1688 & $\begin{array}{c}\mathrm{C}=\mathrm{O} \text { (Ester } \\
\text { group) }\end{array}$ & No \\
\hline 3. & 1446 & 1576 & 1456 & 1448 & 1437 & $\begin{array}{c}\mathrm{C}=\mathrm{C} \\
\text { (Aromatic) }\end{array}$ & No \\
\hline 4. & 1226 & 1223 & 1234 & 1240 & 1225 & C-N (Amines) & No \\
\hline
\end{tabular}

(C)2014 by the authors; licensee IAPC, Zagreb, Croatia. This article is an open-access article distributed under the terms and conditions of the Creative Commons Attribution license (http://creativecommons.org/licenses/by/3.0/) (cc)) EY 